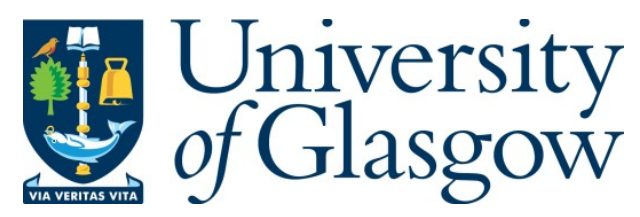

Ivana, G.-I. (2020) Impressions and affective practice: bringing unity to Bourdieu's habitus. Emotions and Society, 2(2), pp. 121-137.

(doi: $\underline{10.1332 / 263169020 X 15994723622263)}$

This is the Author Accepted Manuscript.

There may be differences between this version and the published version. You are advised to consult the publisher's version if you wish to cite from it.

http://eprints.gla.ac.uk/233226/

Deposited on: 5 February 2021

Enlighten - Research publications by members of the University of Glasgow http://eprints.gla.ac.uk 


\title{
Impressions and affective practice: Bringing unity to
}

\section{Bourdieu's habitus}

\author{
Dr. Greti-Iulia Ivana ${ }^{12}$
}

${ }^{1}$ Dr. Greti Iulia Ivana is a lecturer at the School of Social and Political Sciences, University of Glasgow

Correspondence address: Greti-Iulia.Ivana@glasgow.ac.uk

${ }^{2}$ I thank prof. Richard Swedberg from Cornell University, prof. Patrik Aspers and Dominic Dollinger from Uppsala University, and the two anonymous reviewers for their helpful comments on different versions of the manuscript. 


\title{
Impressions and affective practice: Bringing unity to Bourdieu's habitus
}

\begin{abstract}
Despite the key commonalities between the affective and the practical turns, affect is still an underexplored aspect in practice theory. Proposing an analytical distinction between the sociological and the ontological levels of analysis, this article looks into schemes of appraisal as they appear in Bourdieusian practice theory, and highlights how beneath the unity of social conditioning, habitus creates fragmentation between embodied and cognitive meaning. Additionally, it provides a limited and often foggy account of emotions and affectivity. To overcome these challenges, it is argued that practice theory needs to rely on a conceptualization of subjectivity which allows for a more holistic and affective meaning making. Doing so draws on Wetherell's affective practice and Sara Ahmed's Hume inspired concept of impression, but also on a variant of practice which works with empirical rather than epistemic individuals. A theory of practice infused with affect overcomes not only the mind-body dualism, but also contributes to reducing the tension between structural and agentic poles.
\end{abstract}

Keywords: habitus, affect, mind-body dualism, affective practice, impression. 


\section{Introduction}

One of the main features of current sociology is the sharp division into subdisciplines. Some authors describe sociology as a "low-consensus discipline" (Schwemmer and Wieczorek, 2020), others call it a "pluralist discipline". (Puddephatt and McLaughlin, 2015). While this is generally caused by longstanding epistemological differences, fragmentation also appears between subfields which share important commonalities.

For instance, parallel developments can be seen in some of the turns which have marked the social sciences in recent years. The affective (Clough and Halley, 2007; Lemmings and Brooks, (2014), the practical (Schatzki, Knorr-Cetina, and von Savigny, 2001), the relational (Prandini, 2015; Pyyhtinen, 2016) and partially the spatial and material (Low 2016, Griswold et.al 2013) turns draw on largely different scholarship, and apply themselves to multiple facets of reality but they have compatible, if not overlapping assumptions and aims. Namely, a) the increased attention to the materiality of the social world, but also b) the embodied and affective human condition, c) the understanding of meaning, social processes and institutions as derived from practice, $d$ ) the role of lived experience in reproducing and challenging structural patterns, are ideas shared in all the above-mentioned turns. Another key joint element is the relational epistemology: conceptual categories from materiality to meaning, and from affectivity to practice, need to be understood through an analysis of the links between people, environment, artefacts, and of the mechanisms in which these interconnections are articulated. 
Despite the common threads with other areas, but perhaps owing to sociology's history of cognitivist bias (Holmes et.al 2019), theoretical debates on affectivity are still typically contained within a limited set of subfields.

As Sheer (2012) writes: "The theory of practice that emerged at the intersection of philosophical phenomenology, sociology, and anthropology and concerned itself with overcoming the dichotomies of subject/object, mind/body, and individual/society has not included an elaborate discussion of the topic of emotions. If at all, emotions have been treated as part of "the internal" (thoughts, feelings, attitudes, motivations) or en passant as "bodily impulses" (drives, reactions), but hardly theorized as a category in and of itself." (Sheer 2012, p. 199)

In this context, the general aim of this article is to advance subfield integration (Leahey, E., \& Moody, J. (2014) by analyzing how understandings of affect can and should gain prominence in broad sociological debates, especially around the practical turn. Concretely, the article argues for the need to clearly conceptualize the relation between affect and practice within the framework of subjective appraisal schemes and sociological biographies. Conceptualising subjectivity as practically and affectively oriented constitutes a fundamental theoretical task for future forays into a) the socially generative character of affectivity, b) the impact of affectivity on cultural meaning making, social order and institutions.

The article begins with an examination of Bourdieusian practice theory, and its assumptions about subjects' schemes of appraisal and meaning making towards the surrounding world. Bourdieu's theory is chosen not only as the flagship sociological approach to practice, but also due to its potential to accommodate cognitive, affective and somatic elements of subjectivity, and embed the social actor understood this way into larger scale social fields. In its early stages, the 
article examines the links between cognition and embodied practice in Bourdieu's original work, and some of the ways in which different scholars propose enhancing it through phenomenological inputs. Then, the article highlights the generally underestimated role of emotion and affect in these conversations. In this context, Wetherell's affective practice and Ahmed's impressions, are discussed as possible ways to overcome some limitations of the Bourdieusian framework, but also in knowledge and/or practice-based accounts of subjectivity more generally. Lastly, it addresses questions about how these works which mostly deal with the social actor and her relationship with the world, can be used to further the understanding of affect for social and cultural analysis.

\section{Cognition, embodiment and affect in the Bourdieusian subject}

While subjectivity has many facets, this article focuses on the subject as a meaning maker in relation to exterior objects, subjects, events, and how these various meanings about the world are underpinned by cognitive, affective, embodied schemes of appraisal. The undirected states of the subject (such as a general experience of anxiety) or the meaning making in relation to oneself (such as reflexion on one's own actions, experiences etc.) will not be tackled here.

One of the key contributions of practice theory is precisely in the area of how one relates with the world and how meaning is weaved into that relation. Bourdieusian views on the matter are organized around a) social situatedness (we as subjects draw on socialization, past experiences, and our position in a certain field to function practically but also to construct meaning) and b) embodiment (we as bodies accumulate and actualize social structures, but we also understand, move and change our surroundings in a primarily material, embodied way). Habitus is 
the concept which covers these components of Bourdieu's outlook on the subject, but it is also the concept most closely associated with the critique about the understatement of agency. The quasi-deterministic accents of habitus in shaping social action have become a regular critique, with various degrees of vehemence and with proposed solutions ranging from complete repudiation to mild reformulations and additions. For Jenkins (1992) the role of conscious decisionmaking in Bourdieusian theory is a primary concern. He also notes the lack of clarity of the concept of dispositions and Bourdieu's "characteristically elliptical and opaque" (Jenkins 1992:79) style. Another well-known harsh critique comes from Alexander (1995), who reads the embodiment of habitus as a "special kind of socialized biologism", with strong reductionist accents and with a fundamental disregard of true self-autonomy. Archer's $(2001,2010)$ and Myles (2004) critiques follow a very similar route, emphasizing Bourdieu's tendency to polarize practical logic and reflexivity.

While much of this critique is very well elaborated and convincing, discussions about self-autonomy, reflexivity, deliberateness of social actors seek to understand and theorize decision-making, actions and even habits in relation to social structures and constraints. However, as Ignatow (2009) points out, besides the much-debated importance of social and cultural meanings, processes and patterns, another foundational part of decision-making and social action, which has received significantly less attention, is the structure of subjectivity. I argue it is at this level of the analysis that much of the blurriness around in Bourdieu's theory originates. Having a clear formulation of how cognition, affectivity and embodiment function together within the ontological subject is paramount for theorising the sociological subject and her habitus. More specifically, the real-life, applied processes of 
appraisal and meaning making about the world cannot be understood without reference to their conditions of possibility.

The level of analysis focusing on the structure of subjectivity or in a slightly different register, the psychological conditions underpinning habitus, is something of which Bourdieu himself rarely wrote at length, and on which few of his exegetes focus explicitly (Lizardo 2004, Ignatow 2009, Atkinson 2019). But the structures of subjectivity are themselves shaped by the social; the capacity of a human being to make sense of the world, her schemes of appraisal are intertwined with her experiences as a social being. Thus, the distinction between the ontological and the sociological subject is only done for the sake of analytical clarity, while empirically they cannot be detached. This entanglement means that despite Bourdieu's focus being on the socially and culturally shaped subject, his views on the conditions of subjectivity can be teased out from there. For instance, Bourdieu (1990b, p. 68) writes about practical belief, which for him: "is not a "state of mind", still less a kind of arbitrary adherence to a set of instituted dogmas and doctrines ("beliefs"), but rather a state of the body." Albeit operating on a different level of analysis, the statement marks the underlying assumption about a division between meanings which are "of the body" and those which is "of the mind", between the logical, intellectual, cognitive, and the practical, embodied, habitual.

\subsection{The underlying mind-body dualism}

In fact, I argue in Bourdieu's work more generally, the robustness of the sociological subject masks the intrinsic division within the ontological subject.

For Bourdieu, the habitus of the sociological subject leads to action through two main pathways. One of them sees the social actor as structurally constrained by 
their habitus; their actions will come as an embodied, habitual, automated response to the situation in which they find themselves. Their practical knowledge, acquired by virtue of their structural position, will guide their conduct while bypassing any intellectual engagement with the context. Some examples in this sense are his account of habitus as "spontaneity without consciousness or will" (Bourdieu 1990a:56), "feel for the game" (Bourdieu 1985:18), or his affirmation that "In so far as it is the product of the incorporation of a nomos, of the principle of vision and division constitutive of a social order or a field, habitus generates practices immediately adjusted to that order (...) This practical, non-thetic, intentionality, which has nothing to do with cogitatio consciously oriented towards a cogitatum, is rooted in a posture, a way of bearing the body (a hexis)" (Bourdieu 2000: 143144).

The parallel significance of habitus is that of structure shaping social actors in such a way that their consciousness and decision making will follow particular patterns reflecting a larger scale objective social reality (doxa). In this case, it is not exclusively automation and practical knowledge at the basis of social action, but also cognition, with the mention that it is limited by the dispositions acquired through previous experience. In Bourdieu's own words: “As an acquired system of generative schemes objectively adjusted to the particular conditions in which it is constituted, the habitus engenders all the thoughts, all the perceptions, and all the actions consistent with those conditions, and no others." (Bourdieu 1990a: 95) In the discourse on this type of habitus, the body is subtly fading away from attention and so are the attempts at explaining the mechanisms through which social structures become part of the socialized subject. Instead, the accent shifts 
back on the patterns of cognitive engagement which are reproduced behind the illusion of independent judgement and free will.

For Bourdieu, and for others interested almost exclusively in the structural stakes of the sociological subject, whether habitus translates straight into practical knowledge and action, or it translates into an objectively shaped set of "ideas" and "choices", may seem like an unimportant variation. Bourdieu writes: "Habitus is both a system of schemata of production of practices and a system of perception and appreciation of practices. And, in both of these dimensions, its operation expresses the social position in which it was elaborated." (Bourdieu 1990b: 131) However, I argue this distinction between the practice and the perception sides of habitus is particularly relevant when conceptualizing the ontological subject and its implications. Whether the locus of meaning is a) within the material body moving through the world and acting in practical ways, or b) at the intersection of the space-occupying body and its cognitive faculties are two very different propositions. And this tension appears throughout his work.

For instance, Bourdieu (1990b: 129-137) talks about agents who undoubtedly "have an active apprehension of the world (...) who construct their own vision of the world". His only addition to a phenomenological point of view seems to be, as he repeatedly states, that the vision of those agents is shaped by their position in the social field. However, Bourdieu analyses myths and rituals in a way that does not resemble his socially enhanced phenomenology from above. He writes: "Rites, more than any other type of practice, serve to underline the mistake of enclosing in concepts a logic made to dispense with concepts; of treating movements of the body and practical manipulations as purely logical operations; of speaking of analogies and homologies (as one sometimes has to, in order to understand and to 
convey that understanding) when all that is involved is the practical transference of incorporated, quasi-postural schemes." (Bourdieu 1977: 116). Many would argue (accurately) that in this fragment Bourdieu is referring to a specific sort of social action and that while his doxa may be influenced by Husserl's (Myles 2004), his views on the practical logic of rites are not. And this is my point as well: Bourdieu's writings are not self-contradictory but masking an underlying division. He overstates the unity of social actions (through habitus and reproduction), which he then goes on to analyze on two fundamentally unrelated paths. Practical knowledge and propositional knowledge have, in Bourdieu's work, different theoretical foundations and different relations to social action, shaped by different roles of the body and cognition.

Thus, in my reading, Bourdieu's concept of habitus is profoundly dualist. One facet of this dualism is meaning. For Bourdieu, actions which require decision making and intentionality reflect social structure through the meanings with which they operate (Lizardo 2004). A look past the primacy of social structure in his accounts of meaning making, reveals a set of tacit assumptions. For instance, he acknowledges these meaning constructions exist and function, despite their lack of agentic autonomy, in the minds of social actors. Here, I would like to point out Bourdieu's subtle acceptance of the cognitivist bias, manifest in an implicit lack of embodiment of the doxic experience. To illustrate, Bourdieu writes: "These common dispositions and the doxa they establish, are the product of an identical or similar socialization leading to the general incorporation of the structures of the market of symbolic goods in the form of cognitive structures in agreement with the objective structures of the market." (Bourdieu 1998: 121, my emphasis). Elsewhere, he defines doxa as " $a$ set of inseparably cognitive and evaluative 
presuppositions" (Bourdieu 2000: 100) Furthermore, the very comparison Bourdieu proposes between doxa and opinion, in dialogue with Heidegger highlights the same mentalist (yet often misread) character of doxa as a set of theses which become active in the "suspension of praxis" (Bourdieu 1977: 168).

The other side of the dualism is more commonly acknowledged. Namely, practical knowledge and practice itself are structured through practical taxonomies, governed by what one must recognize as a "logic which is not that of logic, if one is to avoid asking of it more logic than it can give, thereby condemning oneself either to wring incoherences out of it or to thrust upon it a forced coherence." (Bourdieu 1977: 109) Practical knowledge is embodied in the most material sense of the word; it has a physical, almost instinctive mimetic quality organizing it. In other words, the propositional knowledge manifest in decisions, principles, beliefs of the subjects, is (bracketing its structural characteristics) largely body-less. At the same time, practical knowledge manifest in spontaneous, applicable know-how, is (again, structural aspects aside) embodied and non-intellectual.

It is this ambivalent conceptualization of the ontological subject, whose co-existing cognition and embodiment are often theorized as separate, that also contributes to the muddy issue of reflexivity on the level of the sociological subject. Part of the reason why the Bourdieusian sociological subject is not more reflexive or agentic is the conceptualization of the ontological subject in the divided way explained above. There are a number of attempts to improve on the original concept of habitus through an increased emphasis on reflexively driven action (Crossley 2001a, Adams 2006, Sayer 2009, Elder-Vass 2007, Decoteau 2013, 2016, Frère 2011, Chandler 2013, Pula 2019, Thoop and Murphy 2002, Atkinson 2010, 2018, Cerulo 2006, Crossley 2013). But if we are to avoid falling back into mentalism, that 
increased social reflexivity must necessarily be of a subject whose appraisal schemes are not fragmented between cognition and the body.

\subsection{The affective habitus}

Additional to the lack of clarity and tendency towards a mind-body dualism in the understanding of meaning coming from practice and knowledge, the other shortcoming is that the Bourdieusian ontological subject is mostly lacking affectivity. Unlike the fragmentation between cognition and embodiment, which may be debated with considerable nuance, the almost total absence of affect from Bourdieu's theoretical construction (but not his empirical work) is more clear-cut. As the discussions above highlight, the human being is seen as moving between habitual embodied practice which involves little to no intellectual engagement, and cognitive appraisal, typically in line with doxic beliefs, which have little to do with the body. Even when Bourdieu does mention emotion, oscillations similar to the ones between quasi-mechanical embodiment and mentalist cognition are present. As Sheer (2012, p. 205) points out, in Pascalian Meditations (Bourdieu, 2000) approaches emotion with a phenomenological tone and vocabulary; in "Masculine Domination", "bodily emotions" are separated from "passions and sentiments". In the Logic of Practice (Bourdieu 1990a), both Sheer (2012) and Wetherell (2012) remark the conceptualization of emotions as sets of bodily responses.

Despite these fluctuations in the use of emotion, it is not the lack of clarity, but the insufficient attention towards affect in general that remains the main issue of Bourdieu's work on the topic. In this context, many authors have remarked the need to also account for the importance of affectivity when discussing habitus (ReadDanahay 2005, Sayer 2005, Ignatow 2009, Reay 2015, Prieur 2017, Flach et al. 
2010, Holt et al. 2013). One common point in the approaches of these authors is the argument about Bourdieu's theory being strongly inclined towards practical and aesthetic aspects, and not enough towards ethical ones. Then, the increased attention towards emotions ties in with that towards reflexivity as a means to capture human evaluations and moral judgements. Furthermore, because of the structured character of habitus, emotions also become part of our dispositions, and are shaped by our positionality within social fields and hierarchies.

However, I would argue the underlying questions about the functioning of the subject which mark discussions about the reflexive habitus can also be observed in those about the emotional one. And if we need a clearer understanding of how cognition and practice work as a foundation for the former, we need a clearer understanding of where affect sits, as a foundation for the latter. In other words, $a$ conceptualisation of a subject whose schemes of appraisal of the world are simultaneously embodied, cognitive and affective must be the corner stone of a sociological theory of practice, that is also reflexive and emotional.

\section{Rethinking the subject as meaning maker}

The need for sociological literature to acknowledge and build upon the interconnected character of cognition, affect and embodiment has been highlighted repeatedly in the last two decades. Authors coming from different areas have argued for the importance of re-examining the role of the body, as not simply an object about which meaning is constructed, but also as a central element of meaning making which is inseparable from cold detached intellect. Wacquant's carnal sociology $(2004,2005$ 2014a), feminism and post-colonialism (Grosz 1994, Sommerville and Hartley 2000, Epstein 2006, Pitts-Taylor 2014), and the sociology of emotions (Holmes (2010) and 
Burkitt $(2012,2014)$ ) and the sociology of cognition (Ignatow 2007, Cerulo 2016) all share this agenda. In many of these cases, such a subject is briefly outlined in the construction of related theoretical arguments. However, I argue a more visible articulation of the affective and non-dualist subject can strengthen the intradisciplinary dialogue between proponents of theories of embodied cognition, emotions and practice.

One such conceptualisation of meaning making which focuses on affect and emotions, but also brings together cognition and embodiment more generally, is proposed by Wetherell $(2012,2015)$. Drawing on insights from psychology, neurosciences and sociology, she sheds light on the different facets of affective meaning construction: the psychobiological processes, the social and cultural shaping, the social sedimentation of affect into more structural realities.

Since I have been arguing for an analytical strategy based on a clearer understanding how schemes of appraisal work in everyday constructions of meaning for social subjects, exploring the physical aspect of affect and cognition is central. Damasio $(1999,2004)$ is perhaps the one of the best-known neuroscientists for social scientists challenging dualisms between mind/body, cognition/affect, rationality/emotion. While some of Damasio's claims (such as those about each primary emotion having a different pattern in the brain) are debatable (Wetherell 2012), the idea of inseparability between cognition and affect for which his work is often invoked is shared by many (Barsalou 2005, Gibbs 2005, Scherer 2009). At the same time, psychologists like Shweder 1994, Russell 2003 also look at how people associatively combine past experiences to generate new meanings, and observe the same continuity of the mental and the somatic. 
From a neurobiological perspective, similar arguments are presented by LeDoux (1996) quoted by Franks (2007) who insists cognition, perception, emotion, are concepts used for analytical purposes, but which do not have dedicated locations within the brain. As Franks (2007) shows in his extensive review of research on the topic, emotion can be linked to the amygdala, the limbic system, but also sensory cortical regions. This means there are two pathways establishing affective experiences in relation with the world: one sends uncategorised data to the thalamus and triggers a sudden response; the other, which covers affective meaning is interwoven with cognition and memory.

Wetherell's affective practice refers precisely to this type of holistic meaning, which is immediately integrated straight back into a Bourdieusian framework of power relations, capitals, and dispositions. The advantage is that the concept of affective practice provides a strong foundation for a habitus that does not overestimate or detach affect, embodiment and cognition. Furthermore, it accounts for the distributed character of meaning (situated between the object and the subject), while also covering the physiology of appraisal processes, and perhaps most importantly, the social, relational, sedimented character of meaning. But bringing affective practice and subjectivity constructed on this basis into Bourdieu's framework runs into an impediment. Bourdieu does not operate with empirical individuals, their experiences and relations; he operates with epistemic individuals who, as Atkinson (2018) highlights are theoretically constructed by the sociologist and "can be, in principle, indistinguishable from one another." (Atkinson 2018, p. 410). People who come from similar backgrounds, share similar forms of capital, will be equivalent for analytical purposes because of their position within social fields. So, if affective practice is appropriated within this framework, the merits of the concept in capturing subjective 
meaning making holistically cannot get reflected into a cultural analysis, which looks at positions rather than subjects.

In her critique of Ahmed's (2004) attempt to expand her view on emotions and apply it to a cultural analysis of affective economies, Wetherell (2015) warns of the risk of decontextualization and disappearance of "the practical human relational work involved in an episode of affect." (Wetherell 2015, p. 159). While this is a very pertinent critique of Ahmed's work, the same risk also applies to the concept of affective practice, as long as it becomes part of the original Bourdieusian theoretical universe, where epistemic, not empirical individuals and relations are central. Practice is of course relational, but that relation needs a full-blown subject as meaning maker. At the same time, Wetherell (2012) insists, affective practice solidifies in individual lives, but this idea creates a tension in relation with habitus seen as predispositions of epistemic subjects. In order for affective practice not to turn into a detached tool of cultural analysis, similar to Ahmed's affective economies, it is fundamental to discuss the shape of the subject in Bourideusian practice theory.

Thus, with Crossley (2001b, 2013), Atkinson (2010, 2015, 2018) I argue for the advantages of a more phenomenological understanding of practice, which looks at subjects as being in the world, and relating to it, which recognises meaning making as an active and agentic process, and which allows patterns and social structures to be continuously constructed and contested. However, the mentalist tendencies of the Husserlian/Schutzian phenomenological views most used in sociology (Campbell 1996, Reckwitz 2002, Lave 1988, Lanksear. 2011, Brinkmann 2007, Heiskala, 2011) are difficult to reconcile with affectivity and embodiment. Here, despite the limits of Ahmed's cultural analysis signalled by Wetherell (2015), her phenomenology of 
emotion, and her depiction of impressions may complement Wetherell's affective practice well. Namely, although both affective practice and impressions refer to the relation between the object and the subject, impressions acknowledge the subject in a way that prevents affective practice from becoming an addition to, rather than a reconfiguration of practice theory.

\section{Hume, Ahmed and the concept of impression}

Sara Ahmed's (2004) work lays at the intersection between post-colonialism, feminism, and the sociology of emotions. When looking back on the history of emotions in social theory, Ahmed proposes a helpful synthesis, which distinguishes between authors who tie emotions primarily to bodily sensations versus the ones who tie emotions with cognition. In the former category, she mentions Descartes, David Hume and William James. In the latter, Aristotle and Sartre. One thing on which Ahmed insists and which I believe is of great importance is the fact that emotion (just like meaning, I would add) involves a relationship between the subject and the object. Following Descartes, she insists objects are not good or bad, but helpful or harmful in relation to us. However, in this train of thought, there is already a cognitive dimension which precedes the feeling. There is an interpretative process through which we position ourselves in relation to that object. Alternatively, if we think of emotions as originating in the body in order to avoid over-cognitivization, the link between bodily sensations and more complex emotions remains complicated to make. In order to avoid the dichotomy between the mentalist and the embodied views, Ahmed adapts David Hume's concept of impression, which implies both cognition and emotion. Forming an impression about someone or something, being impressed by a situation or an event is at the same time being moved, shaken, emotionally touched, while also having a thought 
or a belief. However, Ahmed's use of impression, which is the understanding also embraced in this article, is not entirely overlapping with Hume's original concept. Hume (1975) distinguishes between ideas and impressions, on the one hand and between primary and secondary impressions on the other hand. Both distinctions evoke the break between corporality and reflection which Ahmed attempts to overcome. Having said this, impression as Ahmed describes it, designating meaning which is simultaneously embodied and cognitive, rather than primarily sensitive and only secondarily cognitive, is of great significance in this argument. But impressions as conceptualized by Ahmed are still inextricably linked to episodic events, to particular moments in time and to brief instances of experiencing the world. In this respect, we can place impressions on the same analytical level as spontaneously making sense of a situation (in a cognitivist approach) or spontaneously engaging with a situation in an embodied way, like sitting on a chair or tapping one's feet to the rhythm of the music (in a practice approach). Yet, one of the main strengths of habitus is that it encapsulates a dimension of personal historicity. It goes beyond that momentary analysis and looks at how the episodic level is articulated with the social actor's past and as well as her future. But what the concept of impression does is place individual historicity on a different, and I argue more solid foundation, a foundation which acknowledges the interconnection of embodiment, affect and cognition. Thus, in the following paragraphs I go through several aspects the adoption of the notion of impression can reshape within habitus.

Unlike mentalist meanings, impressions are what we experience, what we remember, what guides us in the future in our relation with our surroundings. The 
impressed subject is familiar with the coziness or coldness of a restaurant or with the meaning of shared laughter in ways that were never fully deconstructed or analyzed by the actors themselves in connection with an accumulated knowledge, but grasped as such. The subject who makes sense of the world is replaced by the subject who relates with the world. She receives input, as corporality means to a large extent being in contact with the resistance of the material world (e.g. a door that will not open). And the same goes for immaterial reality: what we make of it goes hand in hand with also how it impacts us. Thus, what the social actor gathers is a set of subjectively lived, embodied, meaningful relations with the world. Whether or not one retrospectively reflects on that impression, they will still be inherently prepared to feel similarly on a similar occasion. This in turn has consequences on the institutionalization of meaning, because that which becomes institutionalized is not purely intellectual, but impression grounded. For instance, disgust towards another subject or an object is definitely an impression cumulating cognitive and affective appraisals, and even bodily reactions. Furthermore, someone or something being disgusting can become taken for granted and crystalized not only in one person's habitus/ background/historicity, but also on an interpersonal or even societal level.

Regarding habitus, one of the benefits of conceptualizing it as impression-based is the unification of doxa and praxis, which, as discussed above, are complementary, but disconnected. For that bridge to take form, I argue doxa needs to become embodied. Simultaneously, practical knowledge needs to go beyond corporal mimetism and to open up to intellectual engagement. Understanding social actors' relation to the world through impressions fills exactly these gaps, and also accounts for the often-overlooked role of emotions. 
As mentioned above, the link between emotion in habitus has already been explored by several authors (Reay 2015, Sayer 2005, Sweetman 2003). Most of these works reveal emotion as a crucial part of internalized social structure and propose the concepts like emotional habitus and emotional capital to capture this dynamic. My idea of an impression-centered habitus goes in the same direction as these concepts. However, through this lens, the links between emotion, intellectual engagement and embodied practical knowledge are taken further. I argue emotion and embodiment are not only important for shedding light upon new aspects of habitus, but also for reshaping its core assumptions. By placing impressions (which include emotions, but also practical and doxic knowledge) at the root of dispositions to act in a certain way, habitus gains an altogether stronger and more unitary foundation.

However, it must be said that Ahmed's "impression" is a concept rooted in the relation between cognition and affect in meaning making; the issue of practical knowledge is overlooked. Yet, I argue the analysis which Ahmed uses for emotions can easily be extended and applied also as we go into what Bourdieu would call the gymnastics of the body. The interconnectedness of the mind and the body as the body-subject relates to the world also shapes practical know-how. One learns to make a table by being impressed with how the wooden shapes are put together and nailed to each other. That impression entails seeing the actions done, doing them, and understanding why the table stands and how the nails keep it fixed. Seeing, touching, understanding become intertwined within the process of relating with the world. In certain ways, this view is close to Wacquant's understanding of embodied practice. One key commonality is that, in line with Wacquant (2014b), I see the difference in practices which rely more or less on physicality, as a 
difference of degree, not of essence. This being said, in many of his writings on this issue, Wacquant $(2004,2005,2015,2014 a)$ insists especially on the role played by the materiality of human existence in the making of practice. While he recognises of conative, affective and cognitive dimensions, his main focus remains on corporality. This focus becomes particularly clear in his methodological arguments about a carnal sociology, which is presented as a "bottom-up, visceral grasp of the social world". This is seen as an alternative to hermeneutics and discursively based methods. One consequence of a relatively one-sided emphasis on corporality is the increased risk of inadvertently reducing affect back to bodily impulses.

The argument made in the current article is that understanding practice through the lens of impressions highlights more clearly the unity of meaning making. The materiality of the body is of paramount importance, but it is not generative of meaning in itself. Rather, it is one aspect in a complex set of schemes of appraisal. The accent here falls on unity between affect, materiality, cognition, rather than corporality as such (as it would for Wacquant). At the same time, Ahmed's concept of impression alludes more to a Heideggerian ${ }^{1}$ being in the world, which necessarily involves a subject's relation with her surroundings, and not only as a form of knowledge or as a background for the practical actions of an embodied individual. The idea of the subject herself as part of the world, favors impression, where the object also impacts the subject and becomes meaningful in light of this impact.

\footnotetext{
${ }^{1}$ Heidegger himself does not directly discuss embodiment, although Dasein implies a certain dimension of spatiality
} 
Going back to the unity of appraisal mechanisms, different circumstances demand the mobilization of various meaning making capacities in different degrees. For instance, it may be said replacing a light bulb relies on practical knowledge, limited intellectual involvement and almost no emotions. And indeed, within particular impressions, certain components may temporarily fade, but they are never detached from each other. Getting a ladder and replacing the light bulb is meaningful in a practical, learnt repetitive way, but it is also meaningful as a means of intentionally getting light into a dark room again. These two are not separated. Furthermore, assuming there is also an emotional component here (for example, the negligible frustration of having to do the task, or the great joy of someone who after a long illness is able to do this again), that is also interwoven into the cohesive and multifaceted meaning of that action. Thus, not all these dimensions are always of equal importance, but they can always be found in varying degrees, and always connected to each other.

In the previous sections, I discussed the underlying discontinuity which marks practical know-how (linked with the body) and propositional knowledge (linked with the mind) and the underestimation of emotion in Bourdieu's habitus. Through impression, the poles of the body knowing practically and mind knowing intellectually are brought together into an affective body-subject who finds the world meaningful.

Besides the ontological clarity brought by an increased emphasis on affect and its unity with cognition and material embodiment, I suggest a habitus built on impression may also contribute to tackling other unresolved questions in Bourdieu's work, such as the degree of self-determination of social actors and the tension between individualism and collectivism. 
The potential for autonomy of subjects in relation to social structure is often proportional, in a Bourdieusian approach, with the emphasis on cognition and propositional knowledge. Embodied practices are acquired and performed through broadly non-agentic mimetism: people get into habitual, socially accepted practices simply by imitating others. The materiality of the body understood in this way comes to stand for unquestioned and solidified social structure within the subject. In order for the subject to gain agency, she must necessarily be reflexive, and reflexivity is often seen as relying on cognitive processes ${ }^{2}$. The reliance on intellectual capabilities for human agency and self-determination perpetuates the very rift Bourdieu was looking to overcome between voluntarism and structuralism. This can also be observed in the work of scholars who advocate for a more agentic Bourdieusian subject, and who typically insist on of importance of certain forms of understanding the world (the cognitive-voluntarist axis is very present), as the pathway to reclaiming more autonomy.

In this light, a habitus which is unified, affective and based on impressions would have direct implications on how a subject can become agentic and how social structure shapes habitus. Namely, if impressions are the holistic (simultaneously embodied, cognitive and emotional) meanings taken by the world in the experience of the human subject, it follows that habitus becomes a set of learnt ways of relating with the world. In simple terms, our habitus is formed by relations like who we trust or love, who we consider safe or dangerous, what activities we enjoy, what actions we tolerate, what objects we build with our own hands and what we physically manage to carry. While all these relations mould the subject throughout her sociological biography, they allow for more flexibility: they were never enacted

\footnotetext{
${ }^{2}$ For an alternative view on reflexivity which is also emotional, see Holmes (2010)
} 
only through habits of the subject's body, nor can they only be challenged or changed through detached mental analysis. People can and often do learn (and not exclusively through propositional means) new ways of relating to each other and their surroundings, new ways to be impressed, which in turn makes their disposition towards certain actions more fluid. One's autonomy becomes as much a function of cognitive reflexivity, as it is a function of feeling physically tired or uncomfortable with a given practice, or feeling bored, guilty, distracted, embarrassed by having performed it. The resulting change in habitus or the break with some of the structural pressures one has felt under, can then simlply come in the shape of a change of heart/mind about a certain object or situation.

The manner in which one navigates her impression-based relations with the world against the backdrop of social prescriptions and expectations is how habitus is developed. An additional implication of using impressions is that social conditioning does not become oriented towards a single outcome, such as the habitus, but towards a multiplicity of relations with the world which entails different forms and degrees of constraints, enablement and autonomy.

\section{Conclusion}

To summarize, this article proposes a rethinking of habitus based on impressions as a way of strengthening the affective component and overcoming the lingering dualist tendencies in Bourdieusian practice theory. It is argued a habitus rooted in impressions not only recognizes how the practical subject appraises the world and engages with it in a holistic and emotional way, but also allows for a more flexible and agentic subject to emerge, while maintaining the importance of patterns and institutionalized meaning. 
Placing impressions at the foundation of habitus has the potential to address some of the ambiguity which characterizes the subject and her habitus. Firstly, conceptualizing a habitus informed by impressions reinforces the shift from epistemic to empirical individuals, which many scholars have encouraged. Secondly it helps clarify how such an individual relates to the world, without separating knowledge from emotions and corporality.

The argument about the reconfiguration of habitus to include emotion through impressions (as opposed to having emotion as an added layer to an existing conceptual apparatus) starts from the fuzziness which sometimes bears upon Bourdieu's habitus. Making an analytical distinction between the ontological and the sociological subjectivity, I argue the ontological subject of Bourdieu's theory is marked by a rift between knowing (founded in cognition) and acting habitually (founded in the body, understood somatically). In this framework, affectivity remains mostly untackled. By contrast, impressions are found at the intersection between the world and a social actor whose body is not only a vehicle for routine and gymnastics, but whose embodied affect and cognition play a crucial role in the construction and sedimentation of meaning. At a sociological level, the accumulation of impressions as the basis for future meaning making in relation with the world represents the pathway towards bringing affective practice more into cultural analysis, without renouncing structural influences or depersonalizing subjects.

Impression presumes a subject whose meaning making is not interchangeable with that of a person who shares a similar social position. It presumes a constellation of relations that subject may have, a set of experiences and a biography. In this regard, the concept of impressions resolves the tensions between embodied practice and 
intellectual engagement with one's surroundings and complements phenomenological reworkings of Bourdieu's habitus by placing affect at the center of appraisal processes.

At the same time, it must be said that while impressions allow for more selfdetermination, this does not set the stage for an individualist theory of subjectivity. Our impressions are still a result of what we learn from those around us; they are profoundly influenced by the contexts in which we are brought up and to which we have been exposed throughout our lives, as well as by the inequalities which mark social life. As a result, patterns still emerge, and commonalities between subjects who share similar experiences remain likely. But habitus and practice become duly nuanced, affective, and open to change.

\section{References}

Ahmed, Sara. 2004. The Cultural Politics of Emotion. Edinburgh University Press and Routledge.

Alexander, Jeffrey. 1995. The Reality of Reduction: The Failed Synthesis of Pierre Bourdieu. Fin de siècle social theory: Relativism, Reduction and the Problem of Reason, 128-217.

Adams, Matthew. 2006. Hybridizing Habitus and Reflexivity: Towards an Understanding of Contemporary Identity? Sociology, 40 (3), 511-528.

Archer, Margaret. 2001. Being Human: The Problem of Agency. Cambridge University Press.

Archer, Margaret. 2010. Routine, reflexivity, and realism. Sociological Theory,28 
(3), 272-303.

Atkinson, W. 2010. Phenomenological additions to the Bourdieusian toolbox. Sociological Theory 28(1): 1-19.

Atkinson, W. 2015. Putting Habitus Back in its Place? Reflections on the Homines in Extremis Debate. Body \& Society, 21(4), 103-116.

Atkinson, W. 2018. Bourdieu and Schutz: Bringing together the two sons of Husserl. T. Medvetz and J.J. Sallaz (eds.), The Oxford Handook of Pierre Bourdieu. Oxford University Press, 398-420.

Atkinson, W. 2019. Time for Bourdieu: Insights and oversights. Time \& Society, 28(3), 951-970.

Barsalou, L. W. (2005) Situated conceptualization. In: Cohen, H. and Lefebvre, C. (eds.) Handbook of Categorization in Cognitive Science. Elsevier Ltd., pp. 619650.

Bourdieu, Pierre. 1977. Outline of a Theory of Practice. Cambridge University Press.

Bourdieu, Pierre. 1984. Distinction. A Social Critique of the Judgement of Taste. Cambridge, MA: Harvard University Press.

Bourdieu, Pierre. 1985. The Genesis of the Concepts of Habitus and Field. Sociocriticism, 2(2), 11-24.

Bourdieu, Pierre. 1990a. The Logic of Practice. Stanford, CA: Stanford University Press . 
Bourdieu, Pierre. 1990b. In Other Words. Essays Towards a Reflective Sociology. Stanford, CA: Stanford University Press.

Bourdieu, Pierre .1998. Practical Reason. On the Theory of Action. Stanford, CA: Stanford University Press.

Bourdieu, Pierre. 2000. Pascalian Meditations. Stanford, CA: Stanford University Press.

Brinkmann, Svend. 2007. Culture as practices: A pragmatist conception. Journal of Theoretical and Philosophical Psychology, 27-28(2-1), 192-212.

Burkitt, Ian. 2012. Emotional Reflexivity: Feeling, Emotion and Imagination in Reflective Dialogues', Sociology, 46 (3), 458-472.

Burkitt, Ian. 2014. Emotions and Social Relations. London: Sage. Campbell, Colin. 1996. The Myth of Social Action. Cambridge: Cambridge University Press.

Cerulo, K. (2019). Embodied Cognition: sociology's role in bridging mind, brain, and body. In W.H. Brekhus and G. Ignatow (eds.) The Oxford Handbook of Cognitive Sociology. Oxford University Press.

Clough, P. T., Halley, J. (Eds.) (2007). The affective turn: Theorizing the social. Durham, NC: Duke University Press.

Crossley, Nick. 2001 a. The Social Body: Habit, Identity and Desire. London: Sage. Crossley, Nick. 2001b. "The Phenomenological Habitus and its Construction." Theory and Society 30, 81-120.

Crossley, Nick. 2013. Habit and Habitus. Body and Society, 19 (2-3), 136-161. 
Damasio, A. 1999. The Feeling of What Happens. Bondy and Emotion in the Making of Consciousness. New York: Harcourt Brace.

Damasio, A. 2004. Looking for Spinoza: Joy, Sorrow and the Feeling Brain. London:Vintage.

Decoteau, Claire Laurier. 2013. Hybrid habitus: toward a post-colonial theory of practice. Political Power and Social Theory, 24, 263-293.

Decoteau, Claire Laurier. 2016. The reflective habitus: Critical realist and Bourdieusian social action. European Journal of Social Theory, 19 (3), 303- 321.

Elder-Vass, Dave. 2007. Reconciling Archer and Bourdieu in an Emergentist Theory of Action. In Sociological Theory, 25 (4), 325-346.

Epstein, Irving. 2006. Whiteness, Postcolonialism, and Embodiment in Comparative Perspective. In Epstein, Irving (ed.) Recapturing the Personal: Essays on Education and Embodied Knowledge in Comparative Perspective. Information Age Publishing.

Franks, D. D. 2007. The Neuroscience of Emotions. J.E. Stets and J.H. Turner (eds.), Handbook of the Sociology of Emotions. Springer, 39-63.

Gibbs. R. 2005. Embodiment and Cognitive Science. Cambridge University Press.

Griswold, W., Mangione, G. \& McDonnell, T.E. Objects, Words, and Bodies in Space: Bringing Materiality into Cultural Analysis. Qual Sociol 36, 343-364 (2013).

Grosz, E. (1994) Volatile Bodies, St Leonards, Australia, Allen \& Unwin. 
Heiskala, Risto. 2011. The Meaning of Meaning in Sociology. The Achievements and Shortcomings of Alfred Schütz's Phenomenological Sociology. Journal for the Theory of Social Behaviour, 41 (3), 231-246.

Holmes, Mary. 2010. The emotionalization of reflexivity. Sociology 44 (1), 139154.

Holmes, M., Manning, N. and Wettergren, A. (2019) Into the 21st century, Emotions and Society, vol 1 no 1, 3-8

Holt, Louise, Bowlby, Sophia, Lea, Jennifer. 2013. Emotions and the habitus: Young people with socio-emotional differences (re)producing social, emotional and cultural capital in family and leisure space-times. Emotion, Space and Society, $9(1), 33-41$.

Hume, David. 1975. A Treatise of Human Nature, edited by L. A. Selby-Bigge, $2^{\text {nd }}$ ed. revised by P. H. Nidditch, Oxford: Clarendon Press.

Ignatow, G. 2007. Theories of Embodied Knowledge: New Directions for Cultural and Cognitive Sociology? . Journal for the Theory of Social Behaviour, 37: 115135.

Ignatow, G. 2009. Why the Sociology of Morality Needs Bourdieu's Habitus. Sociological Inquiry, 79: 98-114.

Jenkins, Richard. 1992. Pierre Bourdieu. London: Routledge.

Lave, Jean. 1988. Cognition in Practice: Mind, Mathematics and Culture in Everyday Life. Cambridge: Cambridge University Press. 
Leahey, E, Moody, J (2014) Sociological innovation through subfield integration. Social Currents 1(3): 228-256.

LeDoux, J. E. (1996). The emotional brain: The mysterious underpinnings of emotional life. Simon \& Schuster.

Lemmings, D. and Brooks, A. (2014) The emotional turn in the humanities and social sciences. In Lemmings, D. and Brooks, A. (eds) Emotions and Social Change: Historical and Sociological Perspectives, London and New York: Routledge.

Lizardo, Omar. 2004. The Cognitive Origins of Bourdieu's Habitus. Journal for the Theory of Social Behaviour, 34 (4), 375-401.

Low, Martina. 2016. Title Sociology of Space: Materiality, Social Structures, and Action. Palgrave Macmillan US.

Myles, John F. 2004. From Doxa to Experience: Issues in Bourdieu's Adoption of Husserlian Phenomenology. Theory, Culture and Society, 21 (2), 91-107.

Pitts-Taylor, Victoria. 2014. A Feminist Carnal Sociology?: Embodiment in Sociology, Feminism, and Naturalized Philosophy. Qualitative Sociology, 38 (1), 19-25.

Prandini, R. (2015). Relational sociology: a well-defined sociological paradigm or a challenging 'relational turn' in sociology? International Review of Sociology, 25(1), 1-14.

Prieur, A. (2018). Towards a criminology of structurally conditioned emotions: 
Combining Bourdieu's field theory and cultural criminology. European Journal of Criminology, 15(3), 344-363.

Puddephatt, AJ, McLaughlin, N (2015) Critical nexus or pluralist discipline? Institutional ambivalence and the future of Canadian Sociology. Canadian Review of Sociology/Revue canadienne de sociologie 52(3): 310-332.

Pyyhtinen, O. 2016. More-than-Human Sociology: A New Sociological Imagination. London: Palgrave.

Reay, Diane. 2015. Habitus and the psychosocial: Bourdieu with Feelings. Cambridge Journal of Education, 45 (1), 9-23.

Read-Danahay, D. (2005). Locating Bourdieu. Bloomington, IN: Indiana University Press.

Reckwitz, Andreas. 2002. Toward a Theory of Social Practices: A Development in Cultural Theorizing. European Journal of Social Theory 5 (2), 243-263.

Russell, J.A. 2003. Core Affect and the Psychological Construction of Emotion. Psychological Review, 110(1), 145-172.

Sayer, Andrew. 2005. The Moral Significance of Class. Cambridge: Cambridge University Press.

Sayer, Andrew. 2009. Reflexivity and the Habitus. In Conversations about reflexivity. London: Routledge, 108-122.

Schatzki, T. E., Knorr-Cetina, K., von Savigny, E. (2001). The practice turn in contemporary theory. London: Routledge. 
Scherer, K.R. 2009. The dynamic architecture of emotion: Evidence for the component process model. Cognition and Emotion 23(7): 1307-1351.

Schwemmer, C., \& Wieczorek, O. (2020). The Methodological Divide of Sociology: Evidence from Two Decades of Journal Publications. Sociology, 54(1), $3-21$.

Sheer, M. 2012. Are Emotions a Kind of Practice (and Is That What Makes Them Have a History?) A Bourdieusian Approach to Understanding Emotion. History and Theory, 51(2), 193-220.

Shweder, R.A. 1994. 'You're not sick, you're just in love': Emotion as an Interpretive System. In P. Ekman and R.J. Davidson (eds.), The Nature of Emotion: Fundamental Questions. New York: Oxford University Press.

Somerville, Margaret, Hartley Laura. 2000. Eating Place: Postcolonial explorations of embodiment and place. Journal of Intercultural Studies, 21 (3), pp. 353-364.

Sweetman, Paul. 2003. Twenty-first century dis-ease? Habitual reflexivity or the reflective habitus. The Sociological Review, 51, 528-549.

Wacquant, Loïc. 2004. Body and Soul: Ethnographic Notebooks of An ApprenticeBoxer. New York: Oxford University Press.

Wacquant, Loïc. 2005. Carnal Connections: On Embodiment, Apprenticeship, and Membership. Qualitative Sociology, 28 (4), 445-474.

Wacquant, Loïc. 2014a. Putting habitus in its place: A response to the symposium. Body \& Society, 20(2), 118-139. 
Wacquant, Loïc. 2014b. Hominis in Extremis. Body \& Society 20(2), 3-17.

Wacquant, Loïc. 2015. For a Sociology of Flesh and Blood. Qualitative Sociology $38(1), 1-11$.

Wetherell, Margaret. 2012. Affect and emotion: A new social science understanding. London: Sage.

Wetherell, M. 2015. Trends in the Turn to Affect: A Social Psychological Critique. Body \& Society, 21(2), 139-166. 